\title{
Influence of Patch Repair Material on Electrochemical Desalination of Concrete
}

\author{
Hiroshi Minagawa ${ }^{1}$ and Makoto Hisada ${ }^{2}$
}

Received 28 February 2010, accepted 18 May 2010

\begin{abstract}
This study experimentally examined the influence of patch repair materials on the electrochemical desalination method for reinforced concrete. The experimental parameters are the electrical resistivity and the repair area ratio of the patch repair materials. The evaluation items were the amount of desalination and the current density distribution at the surface of the rebar. In addition, an assessment method to estimate the amount of desalination by using core samples obtained from an existing member was proposed. Experiment results showed that the current density at the surface of a rebar increased near the boundary between the patch repair material and the concrete, and that the distribution of current density depended on the electrical resistivity and the repair area ratio of the patch repair materials. Moreover, the amount of desalination increased as the electrical resistivity of patch repair materials increased.
\end{abstract}

\section{Introduction}

Several types of patch repair materials are used when repairing reinforced concrete structures deteriorated by chloride induced corrosion. In this case, the half cell potential of the unrepaired part is lower than that of the repaired part, because the potential in the patched area is noble with a lower chloride ion concentration. As a result, a corrosion circuit current occurs again owing to the difference in potential between the patched area and not-yet patched area. Re-deterioration within the not-yet-repaired area around the patched area is known to occur in existing structures. Some prediction methods of this phenomenon have been proposed by some previous studies (Miyazato et al. 2001; Maruya et al. 2007).

The electrochemical desalination method is one of the electrochemical corrosion control methods for reinforced concrete structures damaged by chloride induced deterioration. This method can remove or decrease chloride ions in concrete by electrochemical migration. Therefore, it has been expected that the application of this method prevents the re-deterioration that originates in the existence of patch repair materials.

When applying this method, it is important to determine the density and period of the applied current, because these design values make a difference on the repair effect. In "Recommendation for Design and Construction of Electrochemical Corrosion Control Methods" (Japan Soc. Civ. Eng. 2001), an approximate current density and period were indicated based on construction experience. In addition, a number of estimation methods for the

${ }^{1}$ Associate Professor, Department of Civil and Environmental Engineering, Tohoku University, Japan. E-mail:minagawa@civil.tohoku.ac.jp

${ }^{2}$ Professor, Department of Civil and Environmental Engineering, Tohoku University, Japan. amount of desalination (Castell et al. 2000; Koga et al. 2008; Minagawa et al. 2007; Suhara et al. 2008; Taue et al. 2007; Toumi et al. 2007) have been proposed. However, it is still difficult to estimate these design values accurately, because the influence of various factors on the amount of desalination from concrete is still unclear (Katano et al. 2008; Koga et al. 2008; Minagawa et al. 2008). Especially, concrete exposed to a real environment has nonuniformities such as the uneven distribution of $\mathrm{Cl}^{-}$concentration or the presence of patch repair materials, and the influence of such nonuniformities on the amount of desalination remains little defined. In particular, although the electrical resistivity of patch repair materials takes on a wide range of values (Naito et al. 2008), the influence of the electrical resistivity of the patch repair materials on the repair effect of the desalination method has received scant attention compared with the use of cathodic protection.

This study focused on the localized presence of patch repair materials, and examined experimentally the influence of patch repair materials on the electrochemical desalination method. The electrical resistivity and the repair area ratio of patch repair materials were selected as the experimental parameters. The evaluation items were the amount of desalination and the current density distribution at the surface of rebar in concrete. Moreover, this study constructed an assessment method to estimate the amount of desalination quantitatively by using some core samples taken from a reinforced concrete member that had a history of patch repair.

\section{Outline of experiment}

\subsection{Outline of specimen}

\section{(1) Shape and size of specimens}

Figure 1 shows the outline of the specimens used in this study. The specimens were divided into the concrete part and the patch repair material part. The repair area 
ratio was set to $50 \%, 30 \%, 10 \%$, and $0 \%$. In addition, the electrical resistivity of the repair materials used in this study was set to three levels. Table 1 lists the experimental factors, level and the number of each specimen. Rebar D13 was arranged at a cover depth of 40 $\mathrm{mm}$ in the longitudinal direction of the specimen. In the specimens where the repair area ratio was $50 \%, 30 \%$, or $10 \%$, the split rebar was arranged as rebar D13 in order to measure the current density flowing into the rebar. The arrangement and size of the split rebars are shown in Fig. 2. The split rebars were integrated electrically through connection with lead wires.

\section{(2) Materials and mix proportion}

Table 2 lists the mix proportion of the concrete used in this study. Ordinary Portland cement (JIS R 5210) was used as the binder. Tap water was used as the mixing water. The fine aggregate was a siliceous sand produced in Tsurusu, Miyagi Prefecture, Japan, with density in saturated surface-dry condition of $2.60 \mathrm{~g} / \mathrm{cm}^{3}$ and water absorption of $2.64 \%$. The coarse aggregate was crushed stone produced in Marumori, Miyagi Prefecture, Japan, with density in saturated surface-dry condition of 2.85 $\mathrm{g} / \mathrm{cm}^{3}$ and water absorption of $0.98 \%$. An air-entraining admixture consisting of an anionic surface active agent was added as the chemical admixture. In addition, $\mathrm{NaCl}$ was added to the mixing water to impart a chloride ion concentration of $10 \mathrm{~kg} / \mathrm{m}^{3}$ per unit volume of concrete.

The characteristics of the patch repair materials used in this study are listed in Table 3. Three kinds of patch repair materials were selected from marketed products in consideration of the electrical resistivity of the hardened patch repair material. $\mathrm{NaCl}$ reagent was not mixed in the patch repair materials.

\section{(3) Fabrication of specimens}

A partition plate and a rebar were placed in a steel form the inside dimensions of which were $100 \times 100 \times 400 \mathrm{~mm}$. Afterwards, the concrete the mix proportion of which was shown in Table 2 was cast on one side of the partitioned formwork. The partition plate was removed after 24 hours, and the joint surface was roughed using a wire brush. After that, a patch repair material was cast on the other side. In the case of the specimen of $0 \%$ repair area ratio, the concrete was cast into a formwork in one setting. The specimens were demolded 48 hours after the concrete was cast into the formwork, and were cured during 28 days under R.H. $90 \%$ and $20^{\circ}$ C. After curing, the specimens were coated with epoxy resin except on the casting side. This casting side was used as the desalination side during electrical current application.

Stainless steel sticks covered with a heat-shrinkable tube were attached to a cut face of the split rebars by soldering. The split rebars were bonded with epoxy resin, and the cut faces of the split rebars were also coated with epoxy resin as shown in Fig. 2. The split rebars were electrochemically bonded by connecting these stainless steel sticks with a lead wire outside of the specimen, as shown in Fig. 3.

\subsection{Current application}

(1) Electrical circuit

Figure 1 shows the outline of the electrical circuit. A

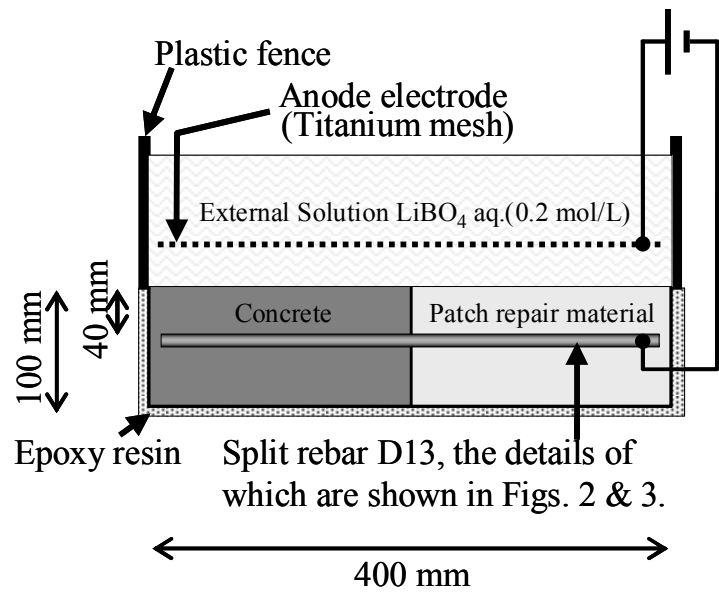

Fig. 1 Outline of specimen (sectional view).

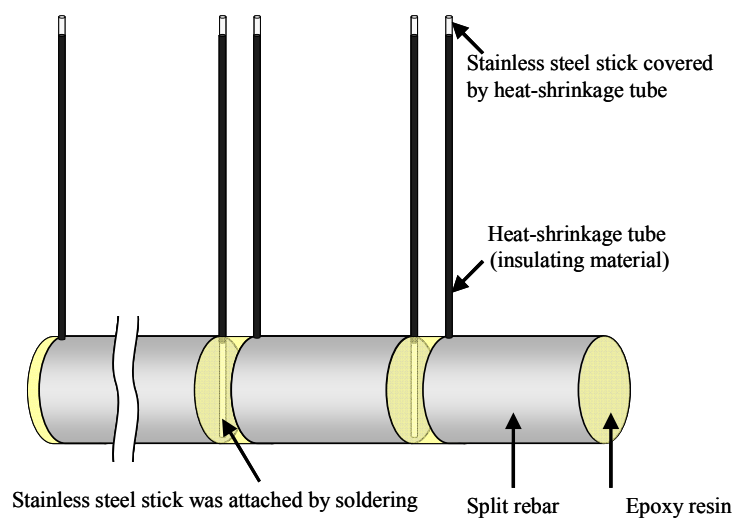

Fig. 2 Schematic of details of split rebar.

Table 1 Number of specimens, experimental factors and level.

\begin{tabular}{|c|c|c|}
\hline Number & $\begin{array}{c}\text { Type of } \\
\text { patch repair material }\end{array}$ & Repair area ratio \\
\hline A50 & A & $50 \%$ \\
\hline B50 & B & $50 \%$ \\
\hline C50 & C & $50 \%$ \\
\hline B30 & B & $30 \%$ \\
\hline B10 & B & $10 \%$ \\
\hline N00 & - & $0 \%$ \\
\hline
\end{tabular}

Table 2 Mix proportion of concrete.

\begin{tabular}{|c|c|c|c|c|c|c|c|}
\hline \multirow{2}{*}{$\begin{array}{c}G_{\max } \\
(\mathrm{mm})\end{array}$} & \multirow{2}{*}{$\begin{array}{c}W / C \\
(\%)\end{array}$} & \multicolumn{6}{|c|}{ Unit content $\left(\mathrm{kg} / \mathrm{m}^{3}\right)$} \\
\cline { 3 - 8 } & & $W$ & $C$ & $S$ & $G$ & $\mathrm{AE}$ & $\mathrm{NaCl}$ \\
\hline 20 & 50 & 175 & 353 & 693 & 1140 & 0.088 & 16.5 \\
\hline
\end{tabular}

Slump $=8.0 \mathrm{~cm}$, Air content $=4.5 \%$ 
sheet of titanium mesh serving as an anode electrode was set $2 \mathrm{~cm}$ from the desalination side. The electrolyte solution was $3.0 \mathrm{~L}$ of $0.2 \mathrm{~mol} / \mathrm{L}$ lithium borate solution. The titanium mesh consisted of an expanded titanium mesh substrate to which a precious metal oxide catalyst was sintered to inhibit the production of gaseous chlorine. During the desalination test, the whole of the external solution was renewed as needed so as to hold the chloride ion concentration in the external solution below 0.05 $\mathrm{mol} / \mathrm{L}$. This criterion was decided in accordance with JSCE-D571-2003 "Test Method for Effective Diffusion Coefficient of Chloride Ion in Concrete by Migration".

\section{(2) Applied current density and period}

An approximate current density and period are indicated based on construction experience, namely, $1 \mathrm{~A} / \mathrm{m}^{2}$ per unit surface of concrete and 8 weeks, respectively (Japan Soc. Civ. Eng. 2001). In addition, in case that the accumulated current density is same quantity even if the current density per surface area of desalination is different value within the range of $1 \mathrm{~A} / \mathrm{m}^{2}$ to $4 \mathrm{~A} / \mathrm{m}^{2}$, the amount of desalination and distribution of the $\mathrm{Cl}^{-}$concentration in concrete during application of the desalination method are almost same. (Katano et al. 2008; Minagawa et al. 2007, 2008; Taue et al. 2007). Here, the accumulated current density is given by the product of the current density and the current application period.

For this reason, in this study, a current density of 4 $\mathrm{A} / \mathrm{m}^{2}$ was applied to the specimens for a duration of 2 weeks, and thus the accumulated current density was $8 \mathrm{~A}$ week $/ \mathrm{m}^{2}$. Thus, the repair effect under these desalination conditions is the same one as when the current density and application period are $1 \mathrm{~A} / \mathrm{m}^{2}$ and 8 weeks, respectively.

\subsection{Measuring items and methods}

\section{(1) Amount of desalination}

Solution samples of $5 \mathrm{~mL}$ were obtained from the electrolyte solution at 1 to 7 day intervals, and the concentration of chloride ion in the solution samples was measured by the potentiometric titration method. The amount of desalination was calculated by Equation (1).

$$
Q_{C l-}=\frac{1}{1000} \times \frac{C \times X}{A}
$$

where, $Q_{C l}$ : amount of desalination per surface area of desalination side $\left(\mathrm{kg} / \mathrm{m}^{2}\right), C$ : concentration of chloride ion in solution sample obtained from external solution $(\mathrm{g} / \mathrm{mL}), X$ : amount of electrolyte solution used for external solution $(\mathrm{mL}), A$ : surface area of desalination side $\left(\mathrm{m}^{2}\right)$

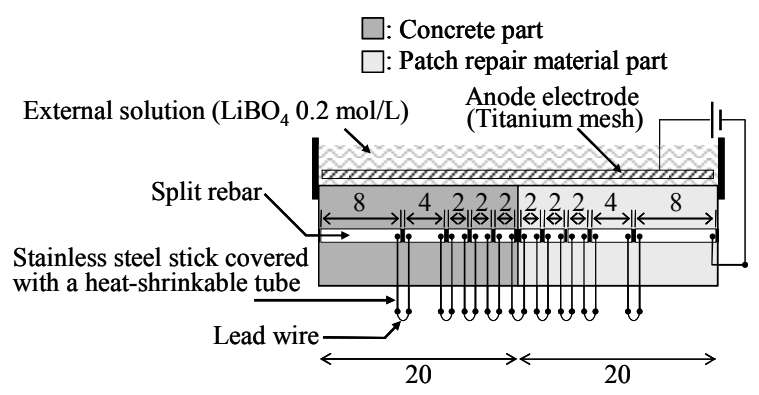

(a) Repair area ratio $50 \%$ specimen $\square$ : Concrete part $\square$ : Patch repair material part

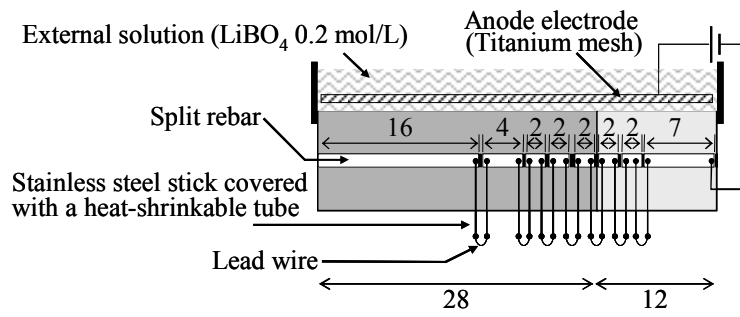

(b) Repair area ratio $30 \%$ specimen $\square$ : Concrete part $\square$ : Patch repair material part

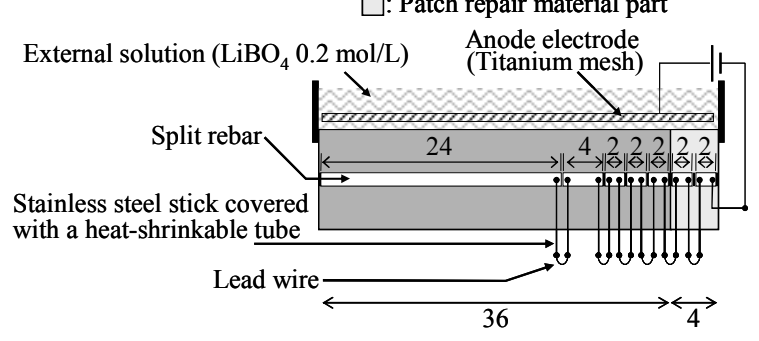

(c) Repair area ratio $10 \%$ specimen

Fig. 3 Arrangement of split rebars (sectional view); Note: Numerals in figures (a), (b) and (c) show length of split rebars and specimen sizes $(\mathrm{cm})$.

Table 3 Mix proportion and electrical resistivity of patch repair materials and concrete.

\begin{tabular}{|c|c|c|c|c|c|c|c|}
\hline Type & $\begin{array}{c}\rho_{28}{ }^{1)} \\
(\Omega \mathrm{m})\end{array}$ & $\begin{array}{c}\rho_{42}{ }^{1)} \\
(\Omega \mathrm{m})\end{array}$ & $\begin{array}{c}W / B \\
(\%)\end{array}$ & $\begin{array}{c}W / P w d \\
(\%)\end{array}$ & $\begin{array}{c}W \\
\left(\mathrm{~kg} / \mathrm{m}^{3}\right)\end{array}$ & $\begin{array}{c}P / P w d \\
(\%)\end{array}$ & Others \\
\hline $\mathrm{A}$ & 67.9 & 71.3 & 42 & 15.6 & 300 & 0.0 & See footnote 3) \\
\hline $\mathrm{B}$ & 300.4 & 328.9 & 42 & 14.0 & 245 & $2.8^{2)}$ & See footnote 3) \\
\hline $\mathrm{C}$ & 593.1 & 579.8 & 40 & 13.0 & 240 & 0.0 & See footnote 3) \\
\hline Concrete & 51.8 & 53.4 & 50 & --- & 175 & --- & See footnote 4) \\
\hline
\end{tabular}

Note: $\rho, W, B, P w d$ and $P$ mean electrical resistivity, water, binder, powder, polymer, respectively. Powder in patch repair materials includes cement, fine aggregate, mineral and chemical admixtures, and polymer.

1) $\rho_{28}$ and $\rho_{48}$ were measured at the material age of 28 and 48 days.

2) The Type $B$ patch repair material contains polyacrylic acid ester polymers.

3) All powders are premixed.

4) Mix proportion is shown in Table 2. 
(2) Distribution of current density flowing to surface of rebar

As noted before, in case that the accumulated current density is same quantity even if the current density per surface area of desalination is different value within the range of $1 \mathrm{~A} / \mathrm{m}^{2}$ to $4 \mathrm{~A} / \mathrm{m}^{2}$, the amount of desalination and distribution of the $\mathrm{Cl}^{-}$concentration in concrete during application of the desalination method are almost same. However, it is not still clear how the current flowing into the rebar is affected by the current density per surface area of desalination. Therefore, the distribution of current density flowing to the surface of the rebar was evaluated by measuring the value of the current flowing to a split rebar.

The current densities of 1, 2, 3 and $4 \mathrm{~A} / \mathrm{m}^{2}$ per unit surface area of the desalination side were applied to specimens to which the accumulated current densities of 0,643 and 1344 hour $\mathrm{A} / \mathrm{m}^{2}$ had been already applied. Here, the 0 hour $\mathrm{A} / \mathrm{m}^{2}$ accumulated current density means the current was not applied to the specimens. After that, a current value flowing to a split rebar at each current density was measured by using an ammeter connected between the stainless sticks. In addition, the current density per unit surface area of the rebar was calculated from the measured current value and the surface area of the split rebar.
(3) Electrical resistivity of concrete and patch repair material

The electrical resistivity of the concrete and patch repair materials used for fabricating specimens was evaluated according to JSCE-K 562-2008 (Japan Soc. Civ. Eng. 2008). The size of the specimens for this measurement was $\phi 10 \times 20 \mathrm{~cm}$. Note that the measurement was carried out after saturating the specimens using the water by vacuum saturation method.

\section{Experimental results and discussion}

\subsection{Distribution of current density flowing into rebar surface}

\section{(1) Influence of current density per unit surface area of desalination side}

Figure 4 shows the distributions of current density flowing to the rebar surface in the B50 specimen to which the accumulated current density of 0,643 and 1344 hour A $/ \mathrm{m}^{2}$ had been already applied. From Fig. 4, it is obvious that the current density per unit surface area of rebar increases with the increase of the current density per unit surface area of the desalination side. On the other hand, the shapes of these distributions were similar regardless of the current density per unit surface area of desalination side.

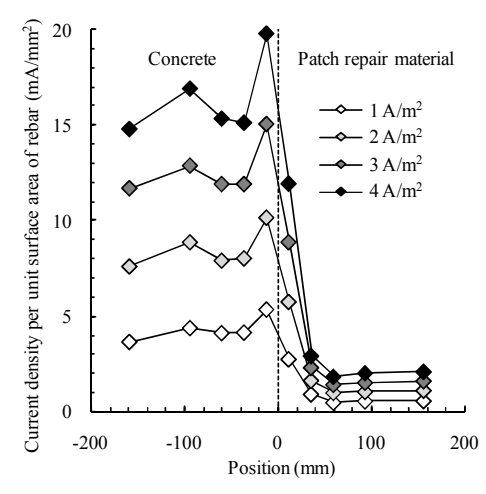

(a) After applying $0 \mathrm{~h} \mathrm{~A} / \mathrm{m}^{2}$

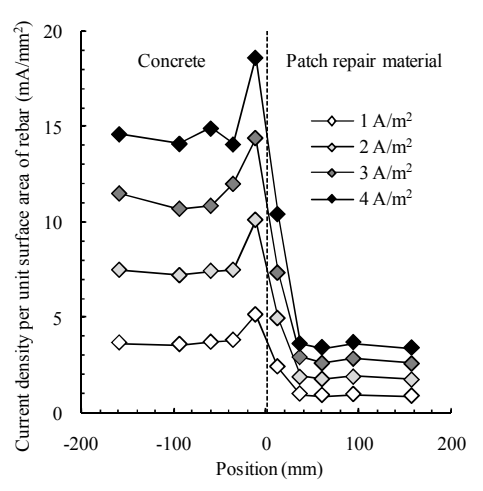

(b) After applying $643 \mathrm{~h} \mathrm{~A} / \mathrm{m}^{2}$

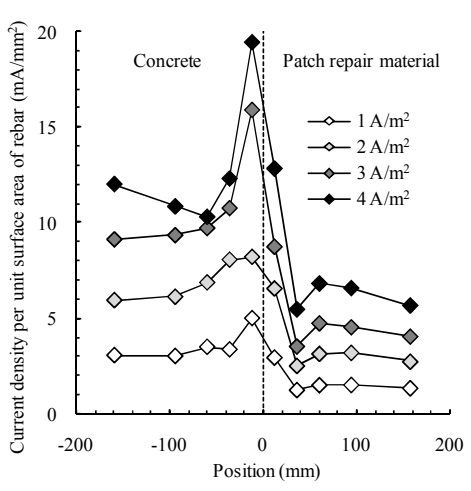

(c) After applying $1344 \mathrm{~h} \mathrm{~A} / \mathrm{m}^{2}$

Fig. 4 Distribution of current density per unit surface area of rebar in case of B50 specimen to which accumulated current density of 0,643 and 1344 hour $A / \mathrm{m}^{2}$ had been already applied.

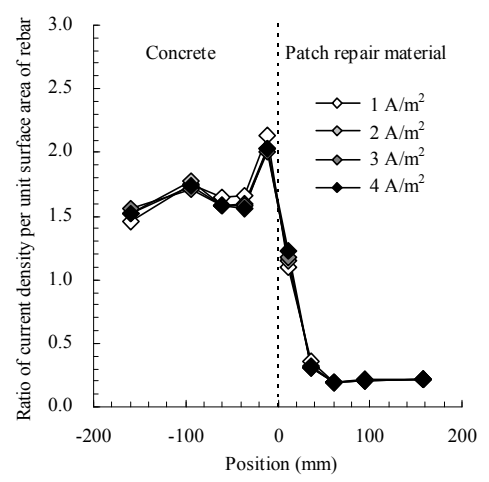

(a) After applying $0 \mathrm{~h} \mathrm{~A} / \mathrm{m}^{2}$

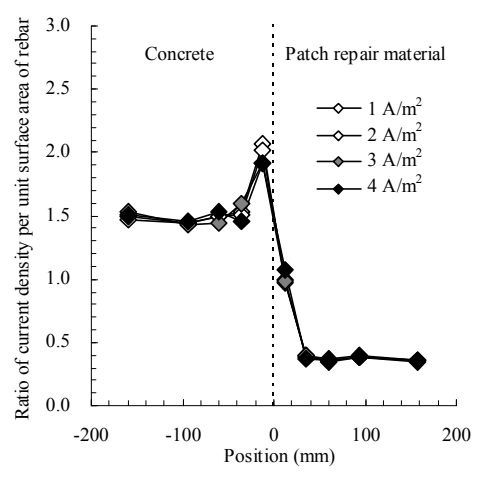

(b) After applying $643 \mathrm{~h} \mathrm{~A} / \mathrm{m}^{2}$

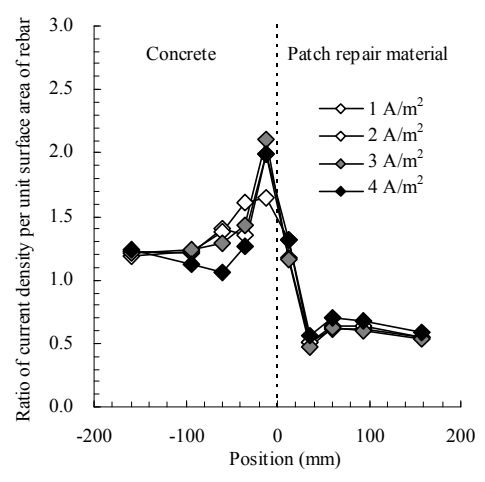

(c) After applying $1344 \mathrm{~h} \mathrm{~A} / \mathrm{m}^{2}$

Fig. 5 Distribution of ratio of current density per unit surface area of rebar $r_{c}$ in case of B50 to which accumulated current density of 0,643 and 1344 hour $\mathrm{A} / \mathrm{m}^{2}$ had been already applied. 
The distribution of the ratio of current density per unit surface area of rebar at position $x$ is shown in Fig. 5 . This ratio is defined by the following equation.

$$
r_{c}(x, n)=\frac{i_{x, n}}{i_{\text {ave }}}=\frac{i_{x, n}}{I / A_{s}}
$$

where, $r_{c}(x, n)$ : ratio of current density per unit surface of rebar at position $x$ when a current density per unit surface area of desalination side of $n \mathrm{~A} / \mathrm{m}^{2}$ is applied to specimen, $i_{x, n}$ : current density per unit surface area of rebar at the position of $x$ when a current density per unit surface area of desalination side of $n \mathrm{~A} / \mathrm{m}^{2}\left(\mu \mathrm{A} / \mathrm{mm}^{2}\right)$ is applied, $i_{\text {ave }}$ : average of current density per unit surface area of rebar $\left(\mu \mathrm{A} / \mathrm{mm}^{2}\right), I$ : current value flowing into specimen $(\mu \mathrm{A})$, $A_{s}$ : summation of surface area of rebar located in specimen $\left(\mathrm{mm}^{2}\right)$.

From Fig. 5, it is obvious that the shapes of the distribution of $r_{c}$ were the same regardless of the current density of the unit surface of the desalination side. Figure 6 shows the comparison result of $r_{c}(x, 4)$ and $r_{c}(x, 1)$, $r_{c}(x, 2), r_{c}(x, 3)$ at the same position of $x$. From Fig. 6, it is obvious that the shape of the distribution of $r_{c}$ did not depend on the current density per unit surface area of the desalination side.
Hence, the distribution of the current density flowing to the rebar surface was evaluated by $r_{c}$ in this study. In addition to this, $r_{c}$ shown in the flowing figures is a mean value calculated by $r_{c}(x, 1), r_{c}(x, 2), r_{c}(x, 3)$ and $r_{c}(x, 4)$.

\section{(2) Influence of electrical resistivity of patch repair material}

Figure 7 shows the influence of the kind of patch repair materials on the distribution of $r_{c}$. The repair ratio of the specimen in Fig. 7 is $50 \%$. From this figure, it is evident that the distribution of $r_{c}$ in the concrete part and the patch repair material part depended on the resistivity of the patch repair materials and that the current mainly flowed to the concrete part, where the resistivity was lower than that of the patch repair materials. Moreover, Figure 7 shows that the flow of current concentrated in the concrete part near the boundary division in case of the B50 and C50 specimens, where the resistivity of the patch repair materials was 5 times or more as high as that of the concrete. It is speculated that the reason for this flow of current is that the current that did not flow from the anode to the patch repairing side flowed into the concrete side near the boundary division through the external solution. Therefore, it can be concluded that a monitoring point for inspecting an overloaded current

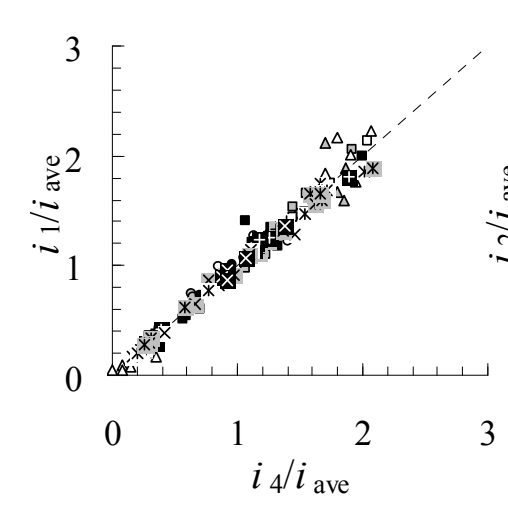

(a) $1 \mathrm{~A} / \mathrm{m}^{2}$ vs $4 \mathrm{~A} / \mathrm{m}^{2}$

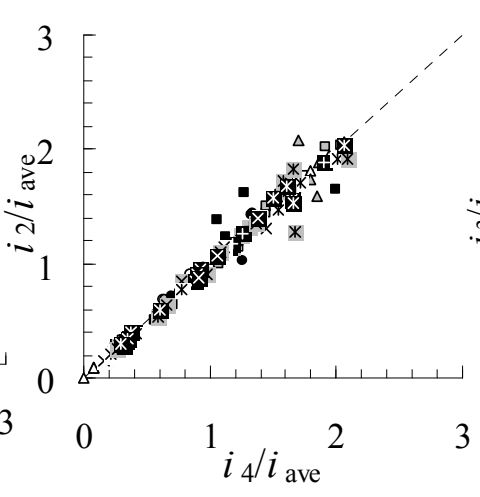

(b) $2 \mathrm{~A} / \mathrm{m}^{2}$ vs $4 \mathrm{~A} / \mathrm{m}^{2}$

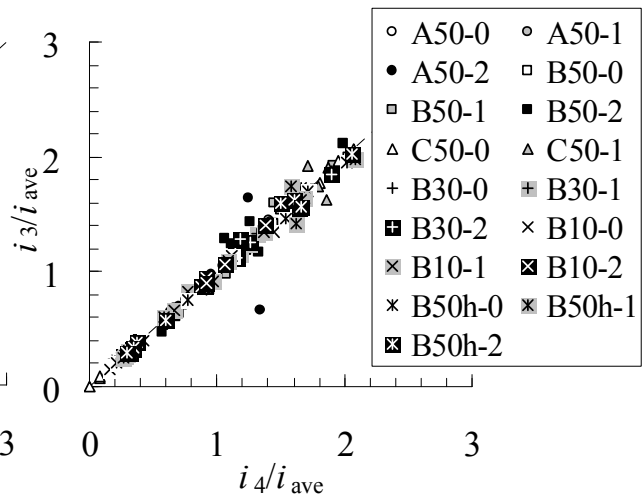

(c) $3 \mathrm{~A} / \mathrm{m}^{2}$ vs $4 \mathrm{~A} / \mathrm{m}^{2}$

Fig. 6 Comparison results of $r_{c}$.

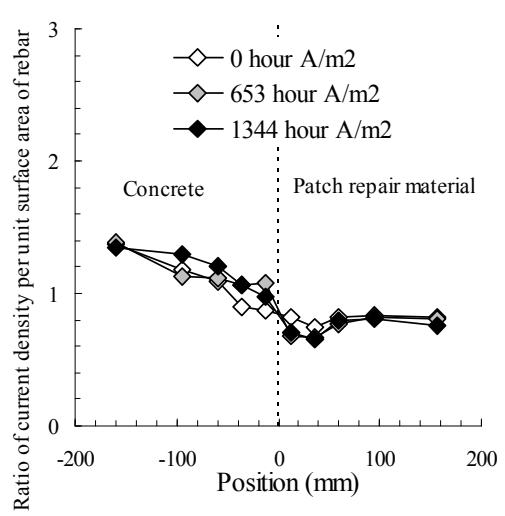

(a) A50 specimen

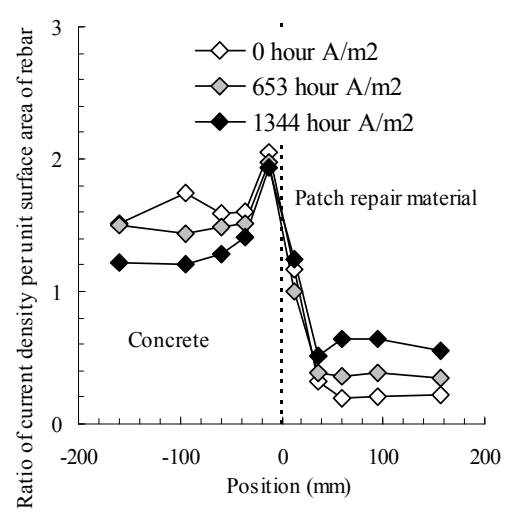

(b) B50 specimen

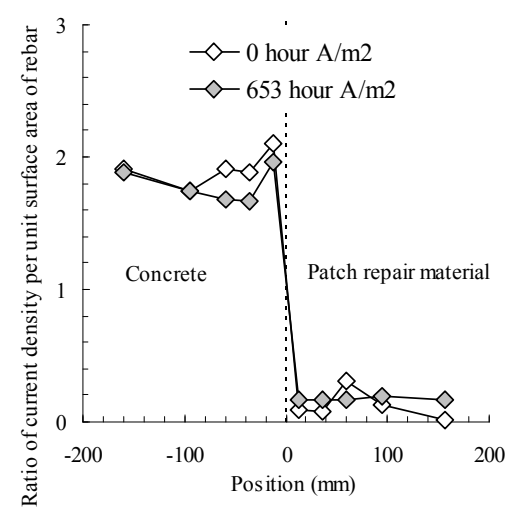

(c) C50 specimen

Fig. 7 Influence of electrical resistivity of patch repair materials on $r_{c}$. 
should be located on the lower electrical resistivity material side near the boundary division, in case the electrical resistivity of the patch repair materials differ greatly from the concrete.

\section{(3) Influence of repair area ratio}

Figure 8 shows the influence of the repair area ratio on the distribution of $r_{c}$ when using the Type B patch repair material, for the repair ratios of $50 \%, 30 \%$ and $10 \%$. From Fig. 8, it is obvious that the peak of $r_{c}$, which can be seen near the boundary division, decreases with decreases in the repair ratio. It is speculated that the decrease in electrical resistivity of the patch repair materials reduces the current flowing into the concrete side from the anode electrode located on the repair side.

Moreover, $r_{c}$ on the concrete side decreased with increases in the accumulated current density, but $r_{c}$ on the patch repair side increased. This is because the increase in accumulated current density reduces the amount of electrolyte in concrete by desalination; the electrical resistivity of concrete becomes high when the amount of electrolyte decreases (Minagawa et al. 2007). As a result, the current flowing into the concrete side decreases. Changing electrical resistivity caused by material aging may also be a factor. However, from the electrical resistivity measurement results listed in Table 3, material aging has a lower impact than the decrease in the amount of electrolyte.

On the other hand, in the case of the Type A and C patch repair materials, this phenomenon was not remarkable, as shown in Fig. 7. In the case of the Type A material, almost the same current flowed into the concrete and patch repair material side because the electrical resistivity was almost the same on both sides. For this reason, the change in electrical resistivity did not differ between the two sides, and the $r_{c}$ value on each side did not change. By contrast, in the case of the Type $\mathrm{C}$ material, the $r_{c}$ value on each side did not change significantly because the electrical resistivity of the Type $\mathrm{C}$ material is high enough compared with the amount of change in electrical resistivity on the concrete side.

\subsection{Amount of desalination and desalination performance ratio}

\section{(1) Influence of electrical resistivity of patch repair material}

Figure 9 shows the influence of electrical resistivity of the patch repair materials on the amount of desalination and the desalination performance ratio. The desalination performance ratio is an index containing two key parameters, namely the amount of desalination and the threshold chloride content, which is determined by the maintenance plan of the structure. This index indicates the repair efficacy of the desalination method more adequately than the amount of desalination. The desalination performance ratio is defined as shown in Equation (3).

$$
N=\frac{Q_{C l-}}{Q_{A}} \times 100
$$

where, $N$ : desalination performance ratio (\%), $Q_{C l}$ : amount of desalination per unit surface area of the desalination side $\left(\mathrm{kg} / \mathrm{m}^{2}\right), Q_{A}$ : amount of target desalination per unit surface area of the desalination side $\left(\mathrm{kg} / \mathrm{m}^{2}\right)$.

The amount of target desalination should be determined by considering the threshold chloride content for corrosion initiation of steel in concrete and the intended depth of desalination. In this study, the chloride threshold content was set to $2.5 \mathrm{~kg} / \mathrm{m}^{3}$ per unit volume of concrete (P. W. R. I. 2008). Also, the intended depth was set to $50 \mathrm{~mm}$ taking into consideration the cover thickness and the diameter of the rebars. Thus, the amount of target desalination was determined so that the chloride ion content in a region of concrete $50 \mathrm{~mm}$ thick would become $2.5 \mathrm{~kg} / \mathrm{m}^{3}$ following desalination. Thus, the amount of target desalination in this study can be calculated by Equation (4).

$$
\begin{aligned}
Q_{A} & =\left(C_{I}-C_{\lim }\right) \cdot \frac{c}{1000} \cdot \frac{A_{c}}{A_{c}+A_{r}} \\
& =\left(C_{I}-2.5\right) \cdot \frac{50}{1000} \cdot \frac{A_{c}}{A_{c}+A_{r}}
\end{aligned}
$$

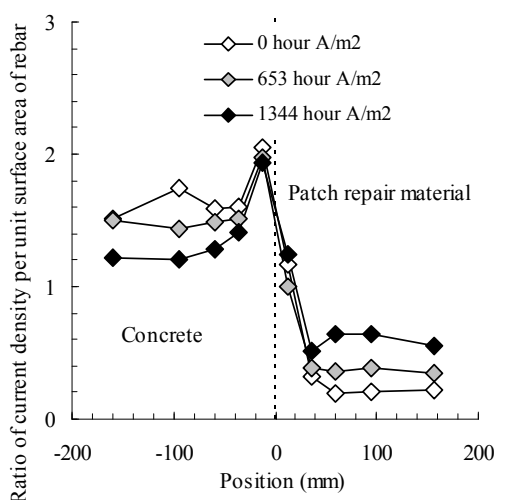

(a) B50 specimen

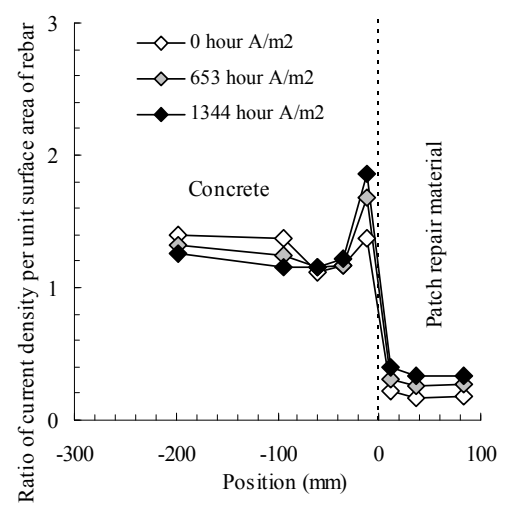

(b) B30 specimen

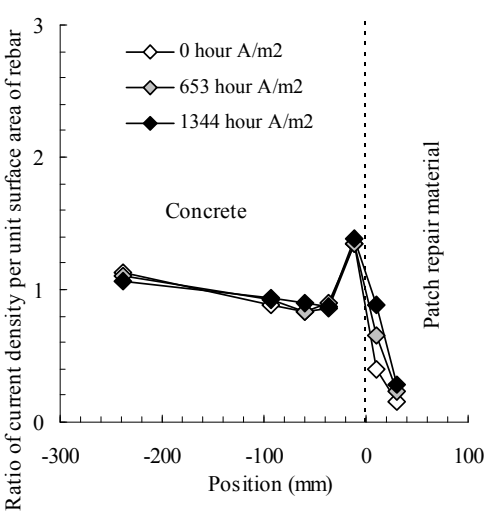

(c) B10 specimen

Fig. 8 Influence of repair area ratio of patch repair materials on $r_{c}$. 
where, $C_{I}$ : initial chloride ion content in concrete $\left(\mathrm{kg} / \mathrm{m}^{3}\right)$, $C_{\text {lim }}$ : threshold chloride content for corrosion initiation of steel in concrete $\left(\mathrm{kg} / \mathrm{m}^{3}\right), c$ : intended depth of desalination $(\mathrm{mm}), A_{c}$ : surface area of desalination in concrete side $\left(\mathrm{m}^{2}\right), A_{r}$ : surface area of desalination on patch repair material side $\left(\mathrm{m}^{2}\right)$.

Figure 9 shows that the amount of desalination and the desalination performance ratio grew with increases in the electrical resistivity of the patch repair materials for the same repair area ratio. The current flowing into the concrete side increases with the use of patch repair materials of high electrical resistivity, as shown in Fig. 7, and the actual accumulated current density through the concrete side increases. For this reason, it is necessary to note the electrical resistivity of patch repair materials when selecting a current density and a current application period or executing quality control during desalination based on the amount of desalination.

\section{(2) Influence of repair area ratio}

Figure 10 shows the influence of the repair area ratio on the amount of desalination and desalination performance ratio. From Fig. 10, it is obvious that the amount of desalination increases with decreases in the repair area ratio. This phenomenon is attributed to an increase in chloride ion content per specimen, because the amount of desalination depends on the chloride ion content per concrete volume (Minagawa 2007). In these experimental cases, the reduction of the repair area ratio increases the amount of chloride ion per specimen as well as the concrete volume. This change in chloride ion content per specimen influenced the experimental results for the amount of desalination.

On the other hand, the desalination performance ratio decreased with the reduction of the repair area ratio. Moreover, in case of B10 and N00 specimen of which the repair area ratio was $10 \%$ and $0 \%$ respectively, the desalination performance ratio of these specimens was almost the same quantity. From this result, it seems that the influence of the repair area ratio becomes remarkable when the repair area ratio becomes about $10 \%$ or more. For this reason, it is recommended that the design and repair work of the desalination method should be executed in consideration of the effect of the repair area ratio on the desalination performance ratio when applying it to a concrete member with the repair area ratio of $10 \%$ or more.

\section{Construction of assessment method for amount of desalination by trial examination using core sample}

From the experimental results above, it is obvious that the amount of desalination depends on the electrical resistivity of the patch repair materials and the repair area ratio. This chapter gives the details of an assessment method for the amount of desalination by trial examination using core samples obtained from an existing con-

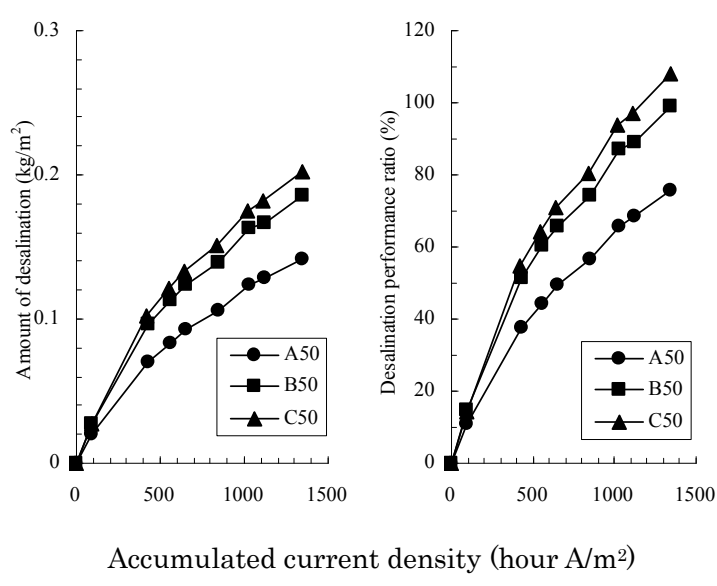

Fig. 9 Influence of electrical resistivity of patch repair materials on desalination.

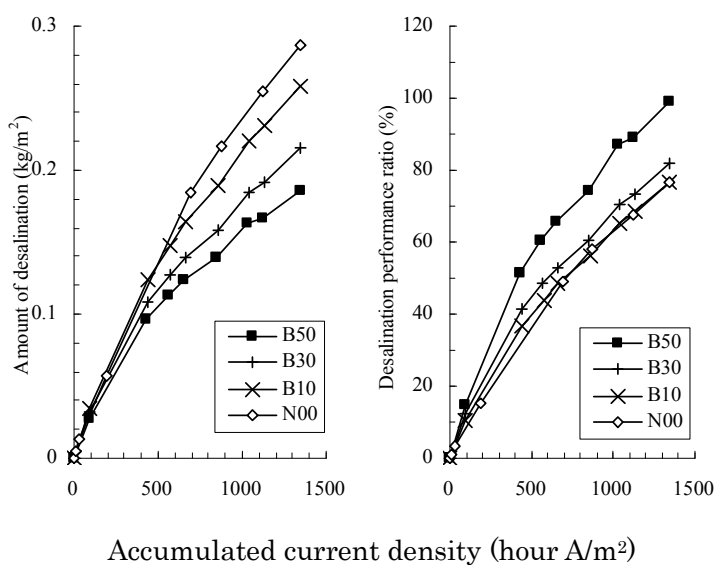

Fig. 10 Influence of repair area ratio of patch repair materials on desalination.

crete member and discusses its validity.

\subsection{Outline of assessment method}

The assessment method in this study is used for estimating the best current density and current application period for the desalination method. In this method, a trial examination of desalination is carried out for concrete core samples obtained from a concrete member. The relationship between the amount of desalination and accumulated current density can be obtained as a result. If the concrete properties in the member are spatially uniform, the examination result can be directly used for selecting the current density and current application period. However, if the concrete member has spatial nonuniformity such as the existence of patch repair material, the reliability of the assessment result becomes lower.

To remedy this problem in this study, the accumulated current density flowing into the concrete side $i_{c} \times T$ was estimated by assuming a parallel circuit model consisting of two electrical resistive elements, as shown in Fig. 11. 


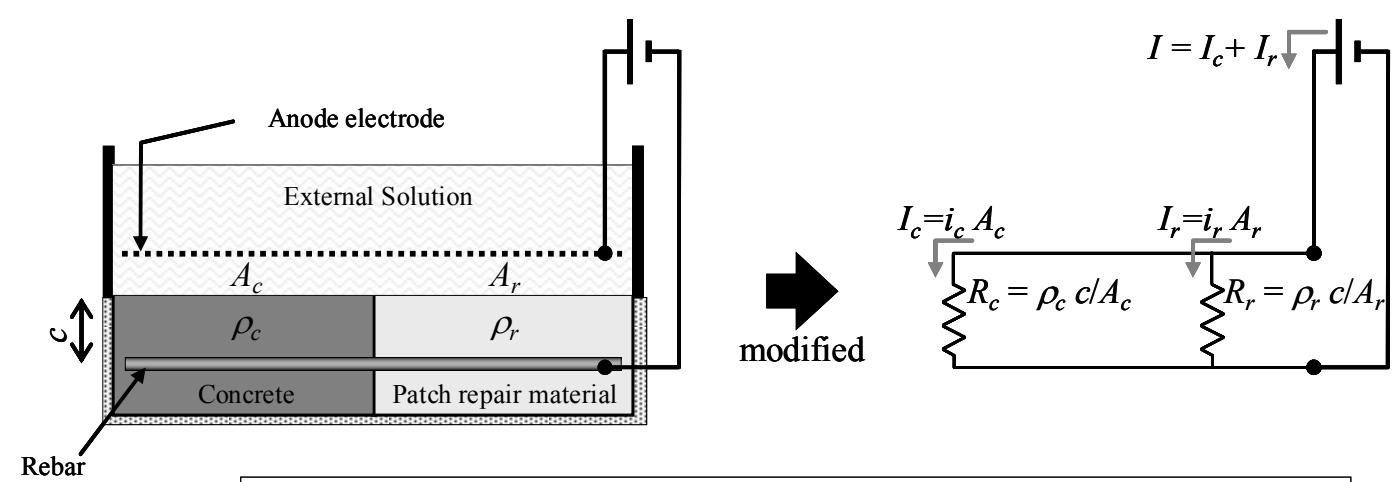

$A:$ surface area of desalination of specimen

$A_{c}$ : surface area of desalination on concrete side

$A_{r}:$ surface area of desalination on patch repair material side

$I$ : current through surface area of desalination of specimen

$I_{c}$ : current through surface area of desalination on concrete side

$I_{r}$ : current through surface area of desalination on patch repair material side

$i$ : current density per unit surface area of desalination side

$i_{c}$ : current density flowing into concrete side

$i_{r}$ : current density flowing into patch repair material side

$\rho_{c}$ : electrical resistivity of concrete

$\rho_{r}$ : electrical resistivity of patch repair material

$c$ : intended depth of desalination (cover depth)

Fig. 11 Outline of parallel circuit model.

The following equations describe the parallel circuit model in Fig. 11.

$$
\begin{aligned}
& I=i \cdot A=i \cdot\left(A_{c}+A_{r}\right)=I_{c}+I_{r}=i_{c} \cdot A_{c}+i_{r} \cdot A_{r} \\
& I_{c} \cdot R_{c}=I_{r} \cdot R_{r} \\
& R_{c}=\rho_{c} \cdot \frac{c}{A_{c}} \\
& R_{r}=\rho_{r} \cdot \frac{c}{A_{r}}
\end{aligned}
$$

where, $A$ : surface area of desalination of specimen, $A_{c}$ : surface area of desalination on concrete side, $A_{r}$ : surface area of desalination on patch repair material side, $I$ : current through surface area of desalination of specimen, $I_{c}$ : current through surface area of desalination on concrete side, $I_{r}$ : current through surface area of desalination on patch repair material side, $i$ : current density per unit surface area of desalination side, $i_{c}$ : current density flowing into concrete side, $i_{r}$ : current density flowing into patch repair material side, $\rho_{c}$ : electrical resistivity of concrete, $\rho_{r}$ : electrical resistivity of patch repair material, $c$ : intended depth of desalination (cover depth).

From the above equations, the accumulated current density flowing into the concrete side $i_{c} \times T$ can be derived as the following equation:

$$
i_{c} \times T=\frac{\rho_{r}\left(A_{c}+A_{r}\right)}{\rho_{r} \cdot A_{c}+\rho_{c} \cdot A_{r}} \cdot i \times T
$$

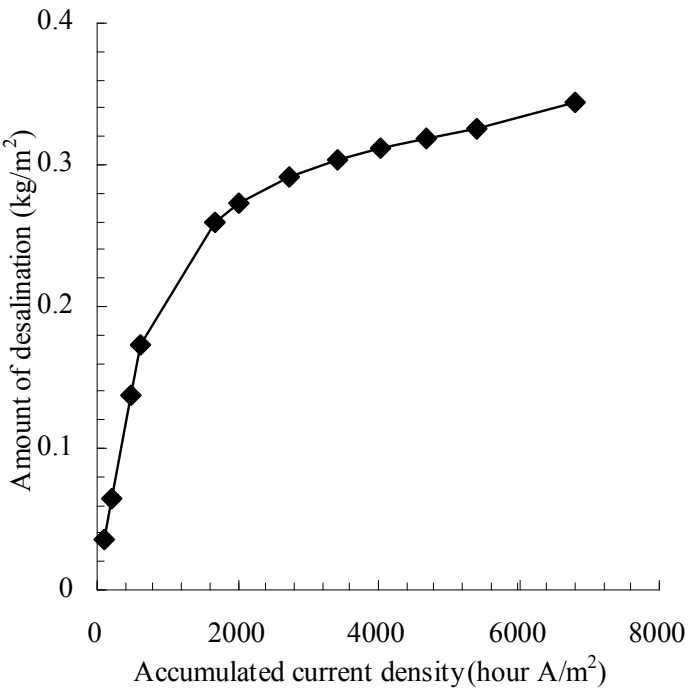

Fig. 12 Result of amount of desalination obtained from trial examination of concrete with same mix proportion as in this study by Taue et al. (2007).

where, $T$ : application period.

The amount of desalination from the concrete side $Q_{c}$ can be estimated by the relationship between the amount of desalination and the accumulated current density $i_{c} \times T$, as shown in Fig. 12. This relationship can be obtained by a result of the trial examination of core specimens which can be sampled from concrete member, as shown in Fig. 13. After that, the amount of desalination per unit surface 


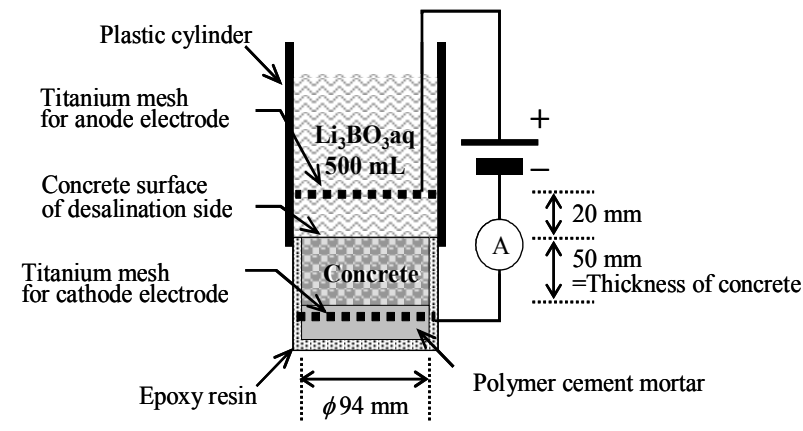

Fig. 13 Outline of trial examination of concrete core sample.

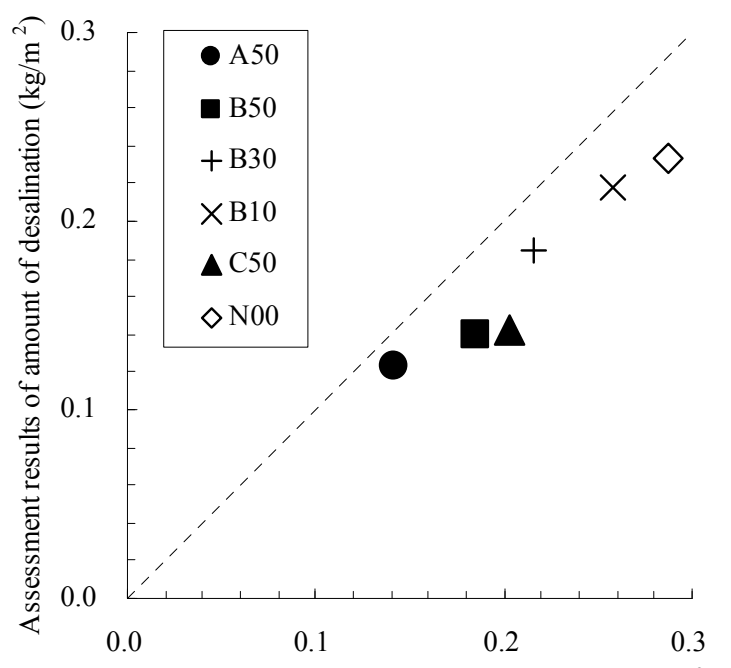

Experimental results of amount of desalination $\left(\mathrm{kg} / \mathrm{m}^{2}\right)$

Fig. 14 Comparison results of assessment data with experimental data about amount of desalination.

area of the desalination side of the concrete member (or specimen) $Q_{C l}{ }^{-}$can be calculated by the following equation:

$$
Q_{C l^{-}}(i \times T)=Q_{c}\left(i_{c} \times T\right) \cdot \frac{A_{c}}{A_{c}+A_{r}}
$$

where, $i_{c} \times T$ can be calculated by $i \times T$ and Equation (9).

\subsection{Comparison of assessment and experi- mental results}

Figure 14 shows the comparison results of the assessment and experiment data for the accumulated current density of 1344 hour $\mathrm{A} / \mathrm{m}^{2}$. It is obvious from this figure that the assessment data and the experiment data compare favorably. The reasons why the assessment data was lower than the experiment data were attributed to no consideration of the influence of the three-dimensional arrangement of rebar and the current flow through the boundary dimension between the concrete and the patch repair material. However, from a practical perspective such as planning a repair design, it is conceivable that the assessment erred on the side of prudence. For this reason, this assessment method will enhance the reliability of the method for selecting the current density and application period of the desalination method.

\section{Conclusions}

The main conclusions of this study can be summarized as follows.

(1) The distribution of the ratio of current density per unit surface area of rebar and its mean value do not depend on the current density per unit surface area of the desalination side.

(2) The distribution of current flowing into the rebar surface depends on the electrical resistivity and the repair area ratio of the patch repair materials. The peak of distribution occurs at the lower resistivity material side near the boundary dimension.

(3) The amount of desalination and the desalination performance ratio grow higher with increases in the electrical resistivity of the patch repair materials in case of the same repair area ratio.

(4) Reduction of the repair area ratio increases the amount of desalination. However, the desalination performance ratio decreases with the reduction of the repair area ratio. If the repair area ratio was $10 \%$ lower, the desalination performance ratio was almost the same in case of no patching repair.

(5) An assessment method for the amount of desalination of a concrete member with a patch repair material by using the result of a trial examination, the electrical resistivity, and the repair area ratio, was constructed. The validity of this method was shown by comparing the assessment data with the experimental data.

\section{References}

Castell, M., Andrade, C. and Alonso, C. (2000). "Electrochemical removal of chlorides. Modelling of the extraction, resulting profiles and determination of the efficient time of treatment." Cement and Concrete Research, 30(4), 615-621.

Japan Soc. Civ. Eng. (2001). "Recommendation for Design and Construction of Electrochemical Corrosion Control Method." Tokyo: Japan Society of Civil Engineers. Concrete Library 107. (in Japanese)

Japan Soc. Civ. Eng. (2008). JSCE Standards on "Test Method for Measuring Resistivity of Patching Repair Materials with Four Electrodes (JSCE-K562-2008)." Tokyo: Japan Society of Civil Engineers.

Katano, K., Taue, K., Minagawa, H. and Hisada, M. (2008). "Influence of various condition of concrete structure on the repair effect of desalination." Proceedings of the Japan Concrete Institute, 30(1), 1167-1172. (in Japanese)

Koga, H., Watanabe, H., Takeuchi, Y. and Kitano, Y. (2008). "A study on the residual chloride ions in 
concrete rehabilitated by electrochemical desalination." Proceedings of the Japan Concrete Institute, 30(1), 1161-1166. (in Japanese)

Maruya, T., Takeda, H., Horiguchi, K., Koyama, S. and Hsu, K-L. (2007). "Simulation of steel corrosion in concrete based on the model of macro-cell corrosion circuit." Journal of Advanced Concrete Technology, 5(3), 343-362.

Minagawa, H., Taue, K., Katano, K. and Hisada, M. (2007). "Study on selection method of appropriate current carrying condition for desalination method using concrete core sample." Proceedings of the Concrete Structure Scenarios, 7, 259-264. (in Japanese)

Minagawa, H. and Hisada, M. (2008). "Influences of content and origin of chloride ion on repairing effect of desalination method." Proceedings of Papers of the 3rd ACF International Conference-ACF/VCA 2008 on Sustainable Concrete Technology and Structures in Local Climate and Environment Conditions, 1041-1047.

Miyazato, S., Otsuki, N., Konagai, H. and Swaid, J. (2001). "Estimation method of macrocell corrosion rate of rebar in existing concrete structures using non-destructive tests." The 8th East Asia-Pacific on
Structural Engineering \& Construction, (2), 531-542.

Naito, H., Moriya, S., Kawamata, K. and Minagawa, H. (2008). "Evaluation report on electrical resistivity of patch repair materials using several types of cementitious materials." Proceedings of the Japan Concrete Institute, 30(2), 595-600. (in Japanese)

Public Works Research Institute. (2008). “Collaborative Research Report on Desalination Method for Concrete Structures Damaged by Chloride Induced Corrosion." 382, 18-22. (in Japanese)

Suhara, K., Tokumitsu, S., Ashida, M. and Tsuji, Y. (2008). "Estimation method of repair effect in desalination of electrochemical corrosion." Proceedings of the Japan Concrete Institute, 30(2), 553-558. (in Japanese)

Taue, K., Katano, K., Minagawa, H. and Hisada, M. (2007). "Study on current-carrying condition selection method of desalination based on trial examination." Proceedings of the Japan Concrete Institute, 29(1), 1359-1364. (in Japanese)

Toumi, A., Francois, R. and Alvarado, O. (2007). "Experimental and numerical study of electrochemical chloride removal from brick and concrete specimens." Cement and Concrete Research, 37(1), 54-62. 